\title{
O SISTEMA SENSORIAL EM AULAS DE CIÊNCIAS POR INVESTIGAÇÃO: Efeitos de Sentido em Análise
}

\author{
Julia Bavaresco ${ }^{1}$ \\ Leandro Siqueira Palcha ${ }^{2}$
}

\begin{abstract}
RESUMO
O estudo foi orientado por autores que reivindicam a emergência de práticas menos expositivas para o Ensino de Ciências e buscam problematizar as questões de aprendizagem focando a alfabetização científica na escola. Sob esta ótica, desenvolveu-se uma sequência de ensino investigativa sobre o bloco temático do sistema sensorial a partir de questões-problemas, envolvendo um conjunto de plantas medicinas. O objetivo da pesquisa é analisar os efeitos de sentido sobre o sistema sensorial em aulas de Ciências por Investigação, visando a mobilizar aspectos da alfabetização científica. A pesquisa guiou-se pelo referencial da Análise de Discurso Francesa, e para a apresentação e discussão do corpus de análise foram destacados efeitos de sentidos que emergiram da escrita de alunos do Ensino Fundamental. Os instrumentos de pesquisa constituem-se pelas respostas dos alunos para o roteiro e um questionário sobre a sequência de ensino. Os resultados mostram que a sequência de ensino dotou os alunos de autonomia e criatividade, assim como manifestou efeitos de sentidos que podem ser trabalhados nas aulas. Por fim, defende-se um trabalho coletivo a favor da alfabetização científica, em que as instituições universidade-escola-comunidade devem criar condições para colocá-la em prática e fortalecer o seu funcionamento.
\end{abstract}

Palavras-chave: Alfabetização científica. Análise de discurso. Metodologias ativas.

\section{THE SENSORY SYSTEM ON SCIENCES CLASSES BY INVESTIGATION: EFFECTS OF MEANING IN ANALYSIS}

\section{ABSTRACT}

The study was guided by authors that require the emergence of less expositive practices for Science Teaching and seek to problematize learning issues by focusing on scientific literacy in school. From this point of view, a sequence of Investigation teaching on the theme of the sensory system was developed, from questions-problems involving a group of medicinal plants. The objective of the research is to analyse the sensory aspects of the sensory system in research sciences and how to mobilize aspects of scientific literacy. The research was guided by the theoretical reference of the French Discourse Analysis, and for the presentation and discussion of the corpus of analysis were highlighted effects of meanings that emerged from the writing of elementary school students. The research instruments are constituted by the students' responses to the script and a questionnaire about the sequence of teaching. The results show that the teaching sequence provided the students with autonomy and creativity, as well as demonstrated effects of meanings that can be worked in classrooms. Finally, it is argued in favor of a collective work of scientific literacy, in which university-school-community institutions should create conditions to put it into practice and strengthen its functioning.

Keywords: Scientific literacy. Discourse analysis. Active methodologies.

RECEBIDO EM: 9/7/2018

ACEITO EM: 23/3/2019

\footnotetext{
${ }^{1}$ Licenciada em Ciências Biológicas pela Universidade Federal do Paraná - UFPR, Setor Palotina. Mestranda do Programa de Pós-Graduação em Biotecnologia da UFPR, Setor Palotina. Professora de Ciências (Ensino Fundamental II) da rede particular de ensino. http://lattes.cnpq. br/1255379286707787. https://orcid.org/0000-0002-5592-4193. jbavaresco96@gmail.com

${ }^{2}$ Licenciado e bacharel em Ciências Biológicas pela Universidade Federal do Paraná - UFPR. Doutor e Mestre em Educação pelo Programa de Pós-Graduação em Educação da UFPR. Professor-adjunto na área de Ensino de Ciências e Biologia - Departamento de Teoria e Prática de Ensino (DTPEN, Setor de Educação - Universidade Federal do Paraná). http://lattes.cnpq. br/0925603428279272. https://orcid.org/00000001-7455-0329. leandropalcha@gmail.com
} 
Há muito observam-se críticas à metodologia expositiva que residem basicamente na forma pela qual o conhecimento científico é trabalhado em sala de aula, como: algo que não se questiona, mas se aceita, e quando que a interação professor-aluno se resume na transmissão-recepção do conteúdo (VASCONCELLOS, 2004).

A fim de romper com essa perspectiva, inúmeros pesquisadores vêm destacando a pertinência e os impactos das metodologias ativas ao processo de aprendizagem, uma vez que "a aprendizagem é ativa e significativa quando avançamos em espiral, de níveis mais simples para níveis mais complexos de conhecimento e competência em todas as dimensões da vida" (MORAN, 2018, p. 2).

$\mathrm{Na}$ literatura internacional, estudos têm apontado as contribuições desencadeadas pela perspectiva da aprendizagem ativa (BIGGS, 2003; DAHMS, 2014; FELDER; BRENT, 2009; JUSTICE et al., 2009; PRINCE, 2004; WESTWOOD, 2011) como possibilidade de reorganizar a prática pedagógica e alinhar o ensino com base na problematização do conhecimento prévio que o aluno traz para a escola.

Entre as metodologias ativas têm-se a modalidade da aprendizagem baseada em investigação e em problemas, em que os estudantes, sob a orientação dos professores, "desenvolvem a habilidade de levantar questões e problemas e buscam - individualmente e em grupo e utilizando métodos indutivos e dedutivos - interpretações coerentes e soluções possíveis" (MORAN, 2018, p. 15).

Nessa direção, o Ensino por Investigação trata-se de uma alternativa que pode proporcionar o desenvolvimento de habilidades de observação, argumentação, análise de dados, resolução de problemas, trabalho em grupo e autonomia dos alunos, destacadas em diversos trabalhos na área de ensino de Ciências (MUNFORD; LIMA, 2007; SOLINO; GEHLEN, 2014). No Brasil, no que diz respeito à literatura, nota-se que a maioria dos estudos, utilizando o referencial teórico do Ensino por Investigação, concentra-se na área de Física, por exemplo os trabalhos desenvolvidos por Carvalho et al. $(1998,2016)$.

Considerando que as atividades na escola devam favorecer uma alfabetização científica (SASSERON; CARVALHO, 2008, 2011), faz-se necessário destacar como as atividades envolvendo leitura e escrita podem permitir aos alunos uma interpretação de aspectos básicos da cultura científica articulada à comunidade escolar.

Ante o exposto, este estudo indaga se as atividades didáticas em aulas de Ciências, por meio de uma abordagem de Ensino por Investigação, podem promover a alfabetização científica do conhecimento biológico. Em conjunto com essa problematização, o Sistema Sensorial aparece como um bloco temático de conhecimentos biológicos relevantes aos alunos do Ensino Fundamental. Há, entretanto, poucas discussões entre os professores de ciências para sua abordagem metodológica, por vezes sendo desenvolvida tradicionalmente. Indo além, nas últimas décadas são quase inexistentes estudos dentro do campo da pesquisa em educação acerca desta temática. Este estudo, então, pode ser oportuno para aprofundar e ampliar as discussões em torno do discurso para a área de pesquisa. 
Dessa forma, tendo em vista que "o discurso é efeito de sentidos entre locutores" (ORLANDI, 2013, p. 21), procuramos destacar que o processo de produção do sentido (efeito) e o sentido em si já produzido, tencionam-se por condições de interlocução. Com isso, é importante analisar como os efeitos de sentido (discursos) podem trazer indicativos para se pensar as práticas pedagógicas.

O objetivo principal desta pesquisa, portanto, é analisar os efeitos de sentido sobre o sistema sensorial em aulas de Ciências por Investigação, visando a mobilizar aspectos da alfabetização científica que podem ser produzidos durante uma sequência de ensino.

Em termos metodológicos, as aulas de Ciências foram realizadas por meio de uma Sequência de Ensino Investigativa (CARVALHO, 2016) sobre o Sistema Sensorial, envolvendo problematização, divulgação dos resultados, contextualização e sistematização do conteúdo, com etapas em que ora predominou o trabalho em grupo, ora individual. A pesquisa desenvolveu-se no contexto do componente curricular Ciências, no Ensino Fundamental, em uma escola pública, sendo os principais instrumentos de coleta de dados um roteiro e um questionário sobre a sequência de ensino.

O corpus de análise será apresentado e discutido por meio do referencial teórico-metodológico da Análise de Discurso Francesa, desenvolvido na França pelos trabalhos de Pêcheux $(2002,2012)$ e no Brasil por Orlandi (2012b, 2013).

Espera-se que o artigo possa contribuir com a pesquisa na área de ensino, discutindo sobre a metodologia de Ensino por Investigação para o Sistema Sensorial, como também pretende discorrer sobre a alfabetização científica, quando serão destacados alguns efeitos de sentido presentes nos dizeres construídos pelos alunos e analisados pela perspectiva discursiva.

\section{ENSINO POR INVESTIGAÇÃO: A Ciência na Escola Para Além da Exposição}

A inquietação pedagógica de muitos pesquisadores na área de Educação em Ciências é a maneira como o conhecimento científico é mediado nas escolas.

Carvalho (2007, p. 27) afirma que este "não reflete nenhum dos aspectos da Ciência como desenvolvimento humano, nem desperta a curiosidade", justificando que o modelo de ensino (tradicional) obriga os alunos a memorizar os conhecimentos.

O método de ensino expositivo, dessa forma, caracteriza a ciência como "um produto acabado e inquestionável: um trabalho didático-pedagógico que favorece a indesejável ciência morta" (DELIZOICOV; ANGOTTI; PERNAMBUCO, 2011, p. 33, grifos dos autores). Nessa perspectiva, a ciência não é problematizada e os alunos não conseguem participar ativamente da sua apropriação no contexto escolar.

No ensino de Biologia, quando a exposição se torna a única estratégia de ensino, muitos alunos podem concluir, por exemplo, que este componente curricular é "só um conjunto de nomes de plantas, animais, órgãos, tecidos e substâncias que devem ser memorizados" (KRASILCHIK, 2011, p. 56). Com isso, em razão do extenso vocabulário 
técnico e a maneira como o conhecimento biológico é trabalhado nas aulas de Ciências ou Biologia, a memorização é a estratégia mais comum para o entendimento dos processos naturais (SANTOS, 2012).

As ideias de Lemke (1997) são contrárias à metodologia de memorização pela qual os alunos apenas repetem o conteúdo de modo automático e alinham-se para um sentido do ensino, no qual os alunos, utilizando as próprias palavras, podem construir significados coerentes com os conhecimentos científicos.

Pelo método de ensino tradicional, na maioria das vezes, os alunos - por não compreenderem o que e por que estão fazendo - não conseguem aplicar o conhecimento científico trabalhado em novas situações. Essas dificuldades são muito comuns em resolução de problemas propostos aos alunos, geralmente, como exercícios rotineiros e repetitivos, sem envolver a importância da reflexão e tomadas de decisão (POZO; GÓMEZ-CRESPO, 1994).

Pozo e Gómez-Crespo (2009), ainda, confirmam que se o conhecimento científico não fizer mais sentido para os alunos, então eles demonstrarão cada vez menos interesse nas aulas de Ciências, aprendendo menos e, consequentemente,

[...] tendem a assumir atitudes inadequadas com respeito ao trabalho científico, assumindo posições passivas, esperando respostas em vez de dá-las, e muito menos são capazes de fazer eles mesmos as perguntas; também tendem a conceber os experimentos como "demonstrações" e não como pesquisas; a assumir que o trabalho intelectual é uma atividade individual e não de cooperação e busca conjunta; a considerar a ciência como um conhecimento neutro, desligado de suas repercussões sociais $(2009$, p. 18$)$.

A respeito da postura do aluno, Vasconcellos (2004) assegura que o problema da metodologia expositiva está em formar o homem passivo, não crítico. Já para Capecchi (2016, p. 23), o ensino do conhecimento científico, exposto de forma acabada, "em vez de estimular o envolvimento dos estudantes com os temas científicos, esse ensino acaba por romper com suas curiosidades, tornando os alunos cada vez mais distantes e desmotivados".

Com isso, as consequências da aplicação da metodologia expositiva baseiam-se principalmente no problema do "alto risco de não aprendizagem, em função do baixo nível de interação sujeito - objeto de conhecimento - realidade" (VASCONCELLOS, 2004 , p. 26, grifos nossos).

Não obstante, Oliveira (2016) alerta para essa concepção errônea de se pensar a atividade científica, uma vez que o fazer ciência "não se encerra nos procedimentos usuais: retirar medidas, interpretar dados, entre outros; mas vai além, também é fundamental para a atividade científica e, por consequência, para o ensino de Ciências a capacidade de o aluno debater suas ideias e escrever sobre o tema" (p. 64).

Sasseron e Carvalho (2008) ressaltam a urgência em desenvolver um ensino de Ciências em que os alunos possam discutir problemas que os façam vivenciar aspectos da cultura científica. O Ensino por Investigação pode ser a condição para que os alunos resolvam possíveis problemas que lhes serão propostos (SASSERON; CARVALHO, 2008). 
A emergência do termo investigação em Ciências surgiu na década de 70 e foi adquirindo vários significados e tendências (PARENTE, 2012), posto que as atividades baseadas na resolução de problemas, de modo geral, exigem do aluno "um papel intelectual mais ativo durante as aulas" (ZOMPERO; LABURÚ, 2011, p. 79).

Para ser denominada investigativa, a atividade deve "estar acompanhada de situações problematizadoras, questionadoras e dialógicas, envolvendo a resolução de problemas e levando à introdução de conceitos" (CARVALHO, 2014, p. 47).

De acordo com Carvalho (2016), uma Sequência de Ensino Investigativa (SEI) deve incluir atividades que, geralmente, têm início com a apresentação de um problema experimental e/ou teórico à turma.

Azevedo (2006) esclarece que estas atividades não precisam obrigatoriamente acontecer em um laboratório, pois a própria sala de aula pode ser utilizada para o desenvolvimento da sequência de ensino. Além disso, também é importante que a turma seja dividida em pequenos grupos para facilitar a comunicação entre os alunos. Depois de resolverem o problema, os grupos são desfeitos e o professor dirige um debate entre os alunos sobre a resolução do problema. É feita, então, a sistematização deste conhecimento de preferência pela leitura de um texto (CARVALHO, 2016).

Diante disso, a problematização dos conhecimentos científicos é de fundamental importância para o desenvolvimento das atividades científicas, uma vez que ela desafia o aluno a rever suas concepções e procurar reorganizar seus conhecimentos anteriores.

Segundo Paraná (2008, p. 72), "a ação de problematizar é mais do que a mera motivação para se iniciar um novo conteúdo. Essa ação possibilita a aproximação entre o conhecimento alternativo dos estudantes e o conhecimento científico escolar que se pretende ensinar". Isto é, o possível limiar entre o ensino tradicional e a investigação refere-se à problematização pela qual se inicia o processo de ensino.

A resolução de problemas em sala de aula, além de contribuir para desenvolver diferentes habilidades cognitivas (SANTOS, 2012) e habilidades das Ciências Biológicas, pode atrair o interesse dos alunos como algo que muitos professores buscam atualmente.

Zompero, Gonçalves e Laburú (2017) defendem que as habilidades cognitivas, como analisar dados para resolver o problema, associar evidências para elaborar explicações e comunicar procedimentos e resultados, ativam as funções executivas de planejamento (em que os alunos atribuem significado, tomam decisões e sequenciam ações para executar um plano), de ação propositiva (em que a atividade é programada em etapas pelos alunos e eles mudam seus comportamentos, alterando esquemas prévios - com a chamada flexibilidade mental) e de monitoramento (os alunos regulam suas ações e, a partir dos resultados, podem alterá-las).

Com relação ao ensino de Ciências, a perspectiva epistemológica, construída por Bachelard (1996), expõe que:

[...] é preciso saber formular problemas. E, digam o que disserem, na vida científica os problemas não se formulam de modo espontâneo. É justamente esse sentido do problema que caracteriza o verdadeiro espírito científico. Para o espírito científico, 
todo conhecimento é resposta a uma pergunta. Se não há pergunta, não pode haver conhecimento científico. Nada é evidente. Nada é gratuito. Tudo é construído (p. 18, grifos nossos).

A afirmativa de que o conhecimento é resposta a alguma pergunta, encontra ressonância com o que é defendido por Azevedo (2006), quando trata a problematização como fundamental na construção de um novo conhecimento e caracteriza esta etapa da investigação como:

[...] um instrumento importante no desenvolvimento de habilidades e capacidades como: raciocínio, flexibilidade, astúcia, argumentação e ação. Além do conhecimento de fatos e conceitos, adquirido nesse processo, há a aprendizagem de outros conteúdos: atitudes, valores e normas que favorecem a aprendizagem de fatos e conceitos (p. 22).

Sob essa ótica, para que o Ensino por Investigação alcance seus objetivos é preciso considerar a importância de os professores criarem condições na sala de aula para os alunos resolverem o problema e compreenderem o que fizeram, como fizeram e porquê foi efetiva a maneira como fizeram (CARVALHO et al., 1998).

Além disso, as discussões em grupo têm sua importância para o desenvolvimento da sequência de ensino na medida em que: "se quisermos realmente que nossos alunos aprendam o que ensinamos, temos de criar um ambiente intelectualmente ativo que os envolva, organizando grupos cooperativos e facilitando o intercâmbio entre eles" (CARVALHO et al., 1998, p. 16).

A criação do ambiente de cooperação possibilita afirmar que os alunos que apresentam "dificuldade em aprender Ciências da maneira tradicional, conseguem produzir significados nas aulas de Ciências" (SCARPA; SILVA, 2016, p. 136).

O aluno, enquanto integrante de um grupo, aprende a considerar as diferentes formas de pensar e trabalhar junto com seus colegas, na cautelosa atividade que é avaliar o quanto suas próprias afirmações são válidas, como também defender seus pontos de vista (CAPECCHI, 2016).

Na perspectiva construtivista, discutida por Carvalho et al. (1998, p. 30), há o objetivo de que "os alunos digam o que pensam com convicção, argumentem com precisão e exponham suas ideias com persuasão (e não repetindo o que professor disse)". Para a efetividade desse processo, entretanto, o professor precisa criar condições para que os alunos se sintam motivados e seguros a expor suas ideias (CARVALHO, 2016).

No que se refere às metas do ensino de Ciências, Carvalho et al. (1998) mencionam a importância de "criar alunos autônomos, que saibam pensar, tomar as próprias decisões e estudar sozinhos" (p. 29). Por sua vez, o Ensino por Investigação é uma oportunidade para alcançar tal meta, posto que as atividades da sequência de ensino têm o principal propósito de gerar mudanças na postura que geralmente se observa do professor e do aluno. 
A abordagem investigativa requer que o professor assuma um perfil "questionador, que argumente, saiba conduzir perguntas, estimular, propor desafios, ou seja, passa de simples expositor a orientador do processo de ensino" (AZEVEDO, 2006, p. 25). Assim, a maneira diferente de o professor portar-se em sala de aula também pode gerar efeitos na postura do aluno que, por sua vez:

[...] sai da posição passiva, deixando de ser apenas um observador das aulas, passando a ter grande influência sobre ela, e não é mais um conhecedor de conteúdos, passando a "aprender" atitudes e desenvolver habilidades como pensar, agir, interferir, argumentar, interpretar e analisar, bem como de fazer hipóteses, defender sua explicação perante o grupo da sala de aula, utilizar a teoria aprendida como justificativa de suas ideias (CARVALHO, 2014, p. 46).

Por conseguinte, para que a cultura escolar adquira características investigativas é necessário que professores e alunos mudem suas práticas (CARVALHO, 2002).

Nesse caso, as metodologias de ensino que fogem do modelo tradicional podem desencadear resistências para o trabalho de muitos professores, pois estes necessitam tomar consciência do desafio desta mudança e da nova postura que adotará, uma vez que "essas transformações não são tranquilas. Há inúmeras resistências às mudanças" (CARVALHO, 2002, p. 59).

Uma das possíveis razões de os professores de Ciências não adotarem a metodologia de investigação, é que nesse tipo de ensino se leva um tempo muito maior para determinado conteúdo ser trabalhado, mas, por outro lado, criam-se condições para os alunos construírem o conhecimento (CARVALHO, 2014); assim, o aluno compreende o conhecimento que pode aplicar em novas situações.

Indo além, Scarpa e Silva (2016) asseguram que, no Brasil, são realizadas muitas atividades de investigação sobre o conhecimento físico e poucas sobre os conteúdos biológicos, e ressaltam: "uma das dificuldades de se propor atividades de investigação com temas de Biologia: nem todos os conteúdos biológicos trabalhados no currículo de Ciências são passíveis de experimentos clássicos" (p. 137).

Nesse entremeio, é importante analisar os gestos de interpretação que permeiam as aulas de Ciências, uma vez que,

A interpretação está presente em toda e qualquer manifestação da linguagem. Não há sentido sem interpretação. Mais interessante ainda é pensar os gestos de interpretação, uma vez que as diferentes linguagens, ou as diferentes formas da linguagem significam modos distintos (ORLANDI, 2012a, p. 9).

De forma geral, mesmo que o Ensino de Ciências por Investigação se destaque como uma abordagem que aproxima o aluno da construção do conhecimento científico e vislumbre a importância de relacionar conteúdo à investigação da natureza, ele ainda é pouco trabalhado em aulas que mobilizam os conhecimentos biológicos.

Esse fato nos impele a analisar e propor atividades investigativas que se distanciem de um ensino meramente expositivo, responsável por produzir uma ciência cada vez mais morta na escola, levando o aluno à passividade e à reprodução dos conheci- 
mentos. O trabalho com o Ensino de Ciências por Investigação oportuniza, sobretudo, a aproximação com o ensino de um sistema coletivo da ciência a partir de uma abordagem construtivista.

\section{ESTRUTURA METODOLÓGICA DA PESQUISA}

Como parte do projeto de pesquisa de uma universidade pública, o estudo, de caráter exploratório, foi realizado no segundo semestre de 2017 com uma turma do 8 ㅇ ano do Ensino Fundamental, no componente curricular Ciências, de uma escola da rede pública do oeste paranaense. Os sujeitos da pesquisa são 31 alunos que, por meio de documentos legais, participaram voluntariamente das atividades solicitadas.

Após visitas à escola, a proposta de ensino, baseada em uma Sequência de Ensino Investigativa (CARVALHO, 2016) para o tema "Sistema Sensorial", foi revista, validada e desenvolvida com a equipe da escola. Na intervenção, considerou-se que os alunos deveriam se sentir mobilizados a construir o conhecimento científico por meio de uma abordagem que despertasse uma atitude científica e estivesse relacionada ao cotidiano.

A SEI teve a duração de duas aulas (geminadas), sendo constituída de forma resumida pelas seguintes etapas: i) entrega das questões problemas para os grupos de alunos; ii) construção de hipóteses dos grupos para resolver a questão problema; iii) divulgação das hipóteses dos grupos à turma e discussão dos resultados obtidos; iv) contextualização do conteúdo por meio de vídeos relacionando tema e cotidiano; e $v$ ) sistematização dos conceitos científicos por meio de desenhos, leitura e escrita.

No início da sequência, sem estabelecer critérios, solicitou-se aos alunos que se organizassem em grupos contendo até cinco integrantes. Após, foi entregue o roteiro da sequência de ensino e incentivado aos alunos resolverem as questões-problema.

Segundo Carvalho (2016), para desenvolver os conteúdos em aulas de Ciências o problema investigativo pode ser classificado em dois tipos: a) problema teórico ou não experimental e b) problema não teórico ou experimental. A presente pesquisa abordou ambas as tipologias.

Para o problema teórico, a atividade estimulava o uso da imaginação, criatividade e conhecimentos prévios dos alunos sobre plantas, sendo ressaltado, para cada grupo, que todos os integrantes deveriam colaborar na elaboração das hipóteses, registrando no roteiro. Nesse passo o papel do professor expressa-se em conferir se os alunos entenderam que precisam resolver o problema, e não em dar a resposta deste (CARVALHO, 2016).

Para o problema experimental, a atividade previa a distribuição e a identificação de espécimes das seguintes plantas: hortelã, (Mentha sp.), salsinha (Petroselinum crispum), cebolinha (Allium schoenoprasum) e cidreira (Melissa officinalis) (Figura 1), escolhidas, principalmente, por serem pertencentes à flora do oeste paranaense, como destacam Ruppelt et al., (2015), bem como pela morfologia externa e o aroma característico que estas plantas apresentam. 
Figura 1 - Espécimes de plantas utilizadas. Da esquerda para a direita: cebolinha, salsinha, cidreira e hortelã

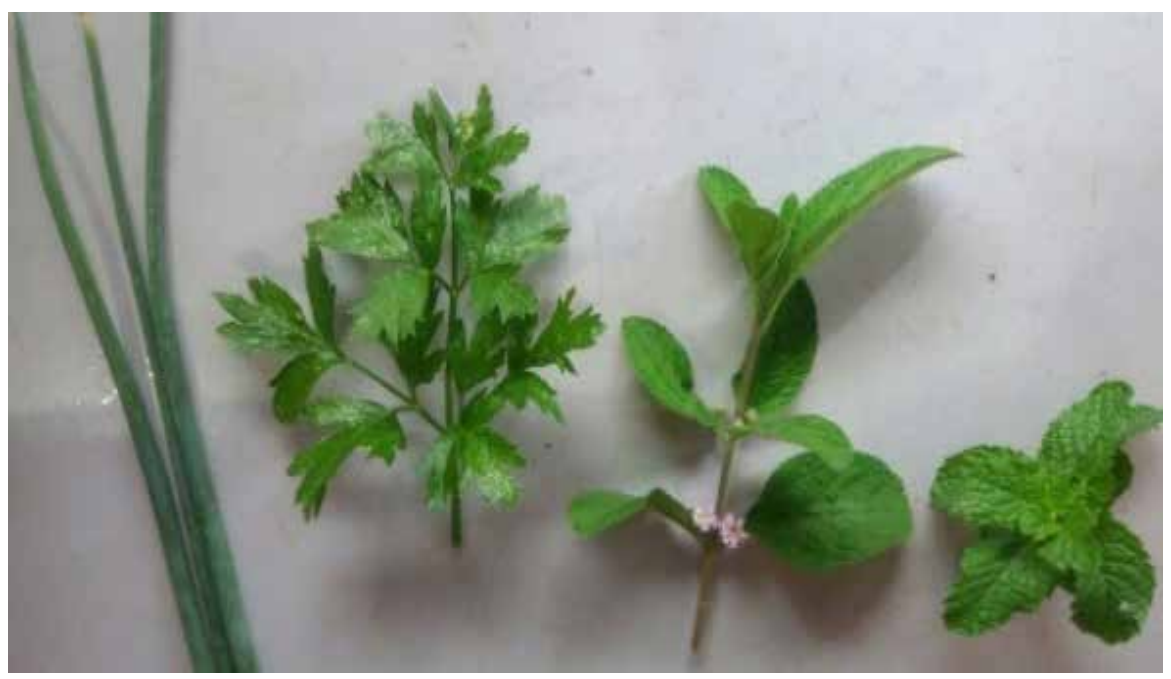

Fonte: Os autores (2017).

Na sequência, também foi organizado um debate com a turma, quando o representante de cada grupo seria responsável por divulgar para os demais grupos as hipóteses formuladas, a fim de que fosse trabalhado, posteriormente, com os conteúdos conceituais relacionados ao sistema sensorial.

Para finalizar, os alunos assistiram vídeos curtos sobre os conteúdos abordados ao longo da sequência de ensino investigativa, e discutiram aspectos microscópicos que envolvem o Sistema Sensorial, além de consulta ao livro didático para articular a abordagem problematizada e a sistematização dos conceitos trabalhados em aula.

É importante observar que a proposta deste trabalho procurou inserir-se nas condições de produção (ORLANDI, 2013) das aulas oferecidas na escola estudada, e é desejável que esta proposta também possa ser realizada por outros professores de Ciências desta ou de outras instituições de ensino.

Foram utilizados dois instrumentos de pesquisa para a coleta de dados: a) o roteiro da sequência de ensino composto por orientações para o desenvolvimento das atividades que nortearam o decorrer do estudo; e b) um questionário com questões gerais e específicas sobre a proposta de ensino.

A análise dos resultados foi guiada pelo referencial teórico-metodológico da Análise de Discurso Francesa (ORLANDI, 2006, 2012b, 2013), como forma de organizar, analisar e estabelecer reflexões sobre os sentidos produzidos, a fim de analisá-los qualitativamente e manifestar sua forma de compreender a realidade. Nesses termos, "não dizemos da análise que ela é objetiva, mas que deve ser o menos subjetiva possível" (ORLANDI, 2013, p. 64).

Considerando que o texto pode ser desde uma letra a várias palavras - "o texto é a unidade que o analista tem diante de si e da qual ele parte" (ORLANDI, 2013, p. 63) -, o corpus de análise foi organizado a partir da leitura e análise de sentidos recorrentes nos textos escritos pelos alunos, sendo os registros dos estudantes dispostos em abordagens (recortes) que contemplaram os efeitos de sentidos. 
Pela perspectiva discursiva, os sujeitos constituem-se pelos gestos de interpretação em cada contexto de produção. Sendo assim, os gestos são atos simbólicos que intervêm no real com um assobio, aplauso, silêncio; assim, tem-se que "a interpretação é um gesto, ou seja, ela intervém no real do sentido" (ORLANDI, 2012a, p. 84).

Dessa forma, analisamos aqui os dizeres no contexto de produção das aulas, sem pretensão de fixar (efeitos de) sentidos, mas destacar o discurso que emergiu a partir deste contexto de análise. "O discurso, por princípio, não se fecha. É um processo em curso. Ele não é um conjunto de textos, mas uma prática” (ORLANDI, 2013, p. 71).

Neste texto, para preservar o anonimato na pesquisa dos participantes, os grupos de alunos serão representados pela letra $G(G 1, G 2, G 3 \ldots G 8$.) e cada aluno pela letra $A$ (A1, A2, A3... A31), sendo as letras numeradas progressivamente. Além disso, foram selecionados os registros de, pelo menos, dois grupos que participaram da sequência de ensino, a fim de ilustrar as respostas produzidas pela turma.

\section{O SISTEMA SENSORIAL POR INVESTIGAÇÃO E OS EFEITOS DE SENTIDOS EM ANÁLISE}

Para apresentação e discussão dos resultados será utilizada a noção teórica de recorte (ORLANDI, 2006), na qual as partes selecionadas do diálogo terão uma noção do todo que contempla o discurso analisado. "Não há discurso fechado em si mesmo, mas um processo discursivo do qual se podem recortar e analisar estados diferentes" (ORLANDI, 2013, p. 62).

Considerando a perspectiva discursiva, o termo efeito será empregado como um indicativo da constituição de sentidos, bem como será intitulado pelas regularidades presentes nos registros/textos dos alunos emergentes dos gestos de interpretação. "Os gestos de interpretação são constitutivos tanto da leitura quanto da produção do sujeito falante. Isto porque, quando fala, o sujeito também interpreta" (ORLANDI, 2012a, p. 88).

\section{Recorte 1: A Sequência de Ensino Investigativa}

Considerando o roteiro da sequência de ensino, o problema teórico propunha que os grupos deveriam discutir e construir hipóteses para a seguinte situação: "Como você identificaria uma planta diferente em uma floresta utilizando seus conhecimentos sobre o Sistema Sensorial?" Essa questão-problema procurava levantar os conhecimentos prévios dos alunos atrelada às aulas de Ciências. Assim, alguns efeitos foram anunciados.

O efeito manipulativo destaca-se em alguns registros

Antes de tocar, usaria uma lupa, iria analisá-la e definir se existe veneno ou algo prejudicial ao tocar a planta; só por precaução, usaria luvas, sentiria sua espessura e observaria por um tempo (G1, grifos nossos).

Analisaria a profundidade de suas raízes. Depois analisaríamos a quantidade de água que ela precisa para sobreviver. Analisar como é o formato das folhas (grandes, médias, pequenas, espinhosas). Analisar se os animais comem a planta (para saber se ela é venenosa ou não). Na visão parece que é macia, mas sentindo a textura é áspera e espinhosa. Apalpando a gente descobre a real textura da planta (G2, grifos nossos). 
O G1 demonstra preocupação com a segurança ao tocar a planta, indicando que utilizaria instrumentos técnicos, como lupa e luvas para coletá-la, e depois a levaria para um laboratório. Ou seja, aspectos que, de fato, podem ser realizados no trabalho de coleta de plantas para a identificação delas por especialistas.

O G2 considera a distribuição geográfica da planta e a profundidade de suas raízes e indica ter noção da diversidade de morfologias externas de plantas existentes. Ao concluir, reconhece a importância do sentido tato em conjunto com a visão para identificação.

Em termos de Ensino por Investigação, os gestos de interpretação destes alunos refletem que eles foram mobilizados a construir hipóteses relacionadas com o processo de investigação, tão importante para as aulas de Ciências. Pressupõem, também, uma atividade intelectual dos alunos e mecanismos de antecipação (ORLANDI, 2013), exigindo que eles criem imagens para uma planta não observada.

O efeito toxicológico é observado adiante.

Dependendo do tipo da planta se ela é venenosa ou não. Eu não seria capaz de usá-la no meio da floresta porque, devido à ação da planta, eu não iria saber o que fazer nesta hora. Devido ao cheiro forte dela e saber se ela é venenosa (G3, grifos nossos).

Ao encontrar uma planta, eu analisaria se ela não seria uma planta venenosa, ou também carnívora, ou possui toxinas letais ao ser humano ou animais. Logo após analisar a mesma, veremos e analisaremos as suas folhas para ver se ela não serve de hospedeiro para algum tipo de protozoário. Logo após todo o processo de análise, observaríamos se ela possui algum tipo de vírus (G4, grifos nossos).

O G3 imagina uma planta com cheiro forte e associa isso com a presença ou não de um possível veneno. Ao mencionar que "não iria saber o que fazer naquela hora", o grupo supõe que não teria conhecimento para coletar, analisar ou identificar a planta; assim, entende-se que o grupo formulou as hipóteses ainda em uma posição contemplativa.

O G4 relata que, além do veneno, há uma hipótese de a planta ser carnívora ou possuir toxinas letais. Demonstra a preocupação com a análise ao formular hipóteses mais elaboradas e apontar que outros seres microscópicos poderiam conviver com a planta.

Este efeito sugere um aspecto nocivo da planta aos humanos, desvelando o sentido do conhecimento dos alunos, à medida que estudar aquele conteúdo teria implicação para a vida fora da escola. A importância de os alunos desenvolverem uma alfabetização científica proporciona "uma cultura científica com repercussões sociais, econômicas, éticas e políticas" (PARANÁ, 2008, p. 41).

O efeito laboratorial aparece em outros relatos.

Observamos que havia uma certa planta, com caule fino e folhas de tons variados de verde; não identificamos sua espécie e muito menos seu nome e ficamos curiosos e animados com a hipótese de ser uma descoberta de uma nova espécie. Decidimos pesquisar em um laboratório (G5, grifos nossos). 
Primeiramente eu tocaria para ver sua espessura, se é áspera ou não, e ver suas folhas também. Eu levaria ao laboratório para analisar essa espécie e depois de muita pesquisa divulgaria (G6, grifos nossos).

O G5 ressalta que uma análise sensorial estaria envolvida no processo de identificação da planta e que seria uma posição assertiva a pesquisa em laboratório antes de divulgar os resultados. A investigação seria realizada por eles, a partir da curiosidade e da empolgação por ter a possibilidade de descobrir uma nova planta.

O G6 destaca que levaria as plantas para pesquisa em laboratório, o que se aproxima da cultura científica, bem como demonstra ter conhecimento sobre aspectos que são considerados ao definir o nome da espécie, por exemplo as características externamente morfológicas da planta.

A partir deste efeito, encontramos outros "gestos de interpretação, que se tecem na historicidade" (ORLANDI, 2013, p. 68). São gestos que demonstraram o conhecimento prévio que tinham sobre o assunto, lembrando-se do termo científico ao responder à questão. Tem-se, portanto, que "o aprendizado dos estudantes começa muito antes do contato com a escola. Por isso, aprendizado e desenvolvimento estão inter-relacionados desde o primeiro dia de vida e qualquer situação de aprendizagem na escola tem sempre uma história anterior" (PARANÁ, 2008, p. 58). A diferença reside, basicamente, na sistematização, que objetiva a aprendizagem do conhecimento científico.

Até aqui os efeitos de sentido elucidam que apenas características morfológicas e toxicológicas não bastam para identificar a planta; é preciso fazer análises em instrumentos de laboratórios e pesquisas em fontes de dados para construir uma afirmação segura. Enfatiza-se também a importância de o trabalho docente considerar os sentidos preconstruídos (ORLANDI, 2013) pelos alunos para o "fazer ciência", posto que a análise destes textos contribui para a aproximação deles com a cultura que é praticada em centros de pesquisa. "Os textos se individualizam - como unidade - um conjunto de relações significativas" (ORLANDI, 2013, p. 70).

Em outro momento, a sequência de ensino abordou o problema experimental para as aulas de Ciências, em que previa a manipulação de plantas presentes no cotidiano dos estudantes. Assim, cada grupo recebeu alguns espécimes de plantas popularmente conhecidas, como cebolinha, salsinha, cidreira e hortelã, facilmente encontradas na região do entorno da escola, e, sem as ver, os alunos deveriam identificá-las com a mediação do professor e diálogo entre eles.

Nesta etapa, principalmente, os grupos mostraram animação em resolver a questão-problema demonstrativa, indicando que a intervenção possibilitaria participar ativamente da aula (MORAN, 2018), sendo também uma forma de romper com o ensino puramente expositivo, oportunizando uma reflexão sobre o significado do conhecimento.

Após, realizou-se um debate para analisar o que havia sido feito até aquele momento e para divulgar na turma as hipóteses construídas pelos grupos. Reside aí uma das ocasiões em que se proporcionou uma oportunidade para que os alunos pudessem passar da ação manipulativa para a ação intelectual (CARVALHO, 2016), à medida que a etapa exigia uma manipulação das plantas bem como organização, compreensão e discussão para se chegar aos resultados. 
Como parte da sequência de ensino, a turma assistiu alguns vídeos sobre como os estímulos sensoriais são enviados ao cérebro, transformando-os em sensação, o que faz parte dos conteúdos das aulas de Ciências e contribui com a visualização do funcionamento interno do sistema sensorial. Em conjunto com as indagações, tal momento proporcionou o conhecimento prévio dos alunos sobre o assunto. Isto é, o trabalho com a linguagem "não se dá como evidência, oferece-nos como lugar da descoberta. Lugar do discurso" (ORLANDI, 2013, p. 96).

A partir de então, as indagações ao longo da sequência de ensino propiciaram a construção de conhecimentos, na medida em que destacam os sentidos preconstruídos dos alunos sobre o sistema sensorial. Isso mostra que os gestos de interpretação podem "tanto estabilizar como deslocar sentido" (ORLANDI, 2013, p. 48).

\section{Recorte 2: As palavras dos alunos sobre o ensino por investigação}

Para a análise da sequência de ensino, foi entregue um questionário para que os alunos respondessem sobre a proposta trabalhada na escola. Sobre os conteúdos conceituais do aprendizado, dois efeitos foram expressos pelos alunos:

- Efeito de sentido sobre os órgãos dos sentidos. A maioria dos textos dos alunos revela aspectos como o interesse e a descoberta por conteúdos de natureza científica, como nos relatos dos seguintes alunos: "Achei muito interessante aprender sobre os órgãos dos sentidos (A10) e "Descobri coisas importantes sobre os órgãos dos sentidos" (A14). Logo, observa-se que, para a maioria dos alunos, mudando o método de ensino foi possível que eles reconhecessem e compreendessem sobre o bloco temático do Sistema Sensorial (órgãos dos sentidos).

- Efeito de sentido sobre os receptores olfativos e táteis. Esse efeito também se manifestou regularmente nos textos, como é indicando pelos seguintes registros: "Nós aprendemos que os receptores táteis mandam as ondas táteis aos nervos e vai para o cérebro" (A11) e "Eu aprendi que quando sentimos alguma coisa a mensagem é transmitida rapidamente ao cérebro pelos receptores táteis e olfativos". (A24). No geral, os alunos registram à sua maneira uma explicação científica de como os receptores táteis e/ou olfativos funcionam, o que pode ter sido consequência da discussão desencadeada após assistirem os vídeos.

No questionário, quando perguntados se se consideravam investigadores, a maior parte da turma deu respostas afirmativas e as justificativas variaram muito entre si, como: "Porque realizamos uma formulação de hipóteses como se fôssemos um investigador" (A19); "Porque gosto de descobrir coisas novas" (A29); "Porque sou curioso" (A1). Por outro lado, uma parte dos alunos respondeu que não se consideravam investigadores, o que foi verificado a partir de depoimentos, como: "Não, pois não me interesso muito na área de Ciências"; (A4) "Não muito, porque eu tenho que aprender um pouco como investigar" (A23).

Faz-se necessário lembrar que a sequência de ensino desenvolvida por este trabalho não tem a pretensão de formar um aluno-cientista na escola, mas, sim, trabalhar aspectos investigativos que favorecem a alfabetização científica, isto é, desvelar as fon- 
tes seguras e debater questões da ciência presentes no dia a dia. Isso nos parece ser um objetivo alcançado, quando a maior parte dos alunos percebe a importância de confiar em fontes seguras e despertar um senso crítico ao longo das atividades.

\section{Recorte 3: (Efeitos de) sentidos da pesquisa em discussão}

No início da sequência de ensino não foi de imediato que os alunos resolveram o problema teórico, pois esperavam por respostas prontas ou, pelo menos, por dicas que conduzissem a uma resposta correta. Ao perceberem que isso não aconteceria, mostraram-se desanimados em resolver o problema, como se desistissem de tentar, debruçando-se sobre a carteira. Como afirmam Pozo e Gómez-Crespo (2009), é comum que, além de os alunos esperarem por respostas, geralmente não são capazes de formular perguntas.

A partir de então, percebeu-se a necessidade de estimular os alunos a resolverem o problema teórico, ou seja, conversar e analisar as suas dificuldades, a fim de instigá-los a construir hipóteses e dotá-los de autonomia. Apenas assim pôde-se observar, aos poucos, que eles interagiam mais entre si para resolver o problema. Há de se refletir, portanto, sobre a postura que o professor assume nesta abordagem de aprendizagem, pois, em vez de expor o conhecimento científico, torna-se em um orientador do processo de aprendizagem, estimulando os alunos a resolverem os problemas.

Carvalho et al. (1998, p. 146) confirmam que "os grupos costumam levar tempos diferentes para solucionar o problema", e isto foi levado em consideração no presente trabalho. Conforme os grupos declaravam ter concluído a atividade, o professor procurava distribuir atenção entre todos os alunos da turma.

Houve também determinada competição entre os grupos, uma vez que era nítida a preocupação de alguns alunos em escrever melhor que os outros e isto foi importante em sala de aula para trabalhar com valores (respeito, ética, paciência, etc.), a fim de demonstrar que, mesmo havendo competição, a ciência é uma construção humana/coletiva e a cooperação é um fator importante para mobilizar o conhecimento científico.

Com relação à atividade demonstrativa, pensou-se em uma relação com o cotidiano que mostrasse como o ensino da ciência pode ser interessante e estimular o aluno a pôr em prática raciocínios (CARVALHO, 2016). Logo, ao manipular as plantas conhecidas e encontradas no dia a dia, os alunos podem tornar o conhecimento significativo de ser estudado nas aulas de Ciências. Alguns autores argumentam que se a questão-problema que orientará a investigação coloca-se "distante ou fora da estrutura cognitiva do aluno, não há como ser reconhecida como um problema a ser investigado" (TRIVELATO; TONIDANDEL, 2015, p. 108).

No estudo de Brito e Fireman (2016) foi claro o sentimento de prazer e satisfação dos alunos ao resolverem o problema. Isto também foi observado quando eles percebiam que as plantas identificadas eram realmente as que haviam imaginado ou dito.

Do mesmo modo, ao sistematizar, relatar e relacionar o que se investigou, indica-se uma percepção de aprendizagem ativa dos alunos, uma vez que eles precisaram encontrar métodos para construir conhecimentos e responder aos problemas que eram 
colocados. Por meio de hipóteses propuseram diferentes caminhos, processos, perspectivas, etc., que seriam atribuídas para a construção de uma explicação científica (BACHELARD, 1996).

Para o desenvolvimento deste estudo foi necessário o registro dos resultados no roteiro da sequência de ensino pelos alunos. A escrita, dessa maneira, assume um papel importante ao estabelecer formações imaginárias (ORLANDI, 2013), ora sobre a identificação das plantas, ora sobre a sistematização de hipóteses a serem reveladas.

Após a fase de debates, as plantas foram recolhidas para que os alunos as desenhassem em seu roteiro, imaginando-as da maneira que as sentiram, sem olhar para elas. As ilustrações do A1 (Figura 2), por exemplo, destacam a noção do formato das bordas das folhas, bem como a disposição das folhas da salsa, aspectos importantes no momento da identificação pelo sentido tato.

Figura 2 - Ilustrações de um aluno sobre as plantas problematizadas

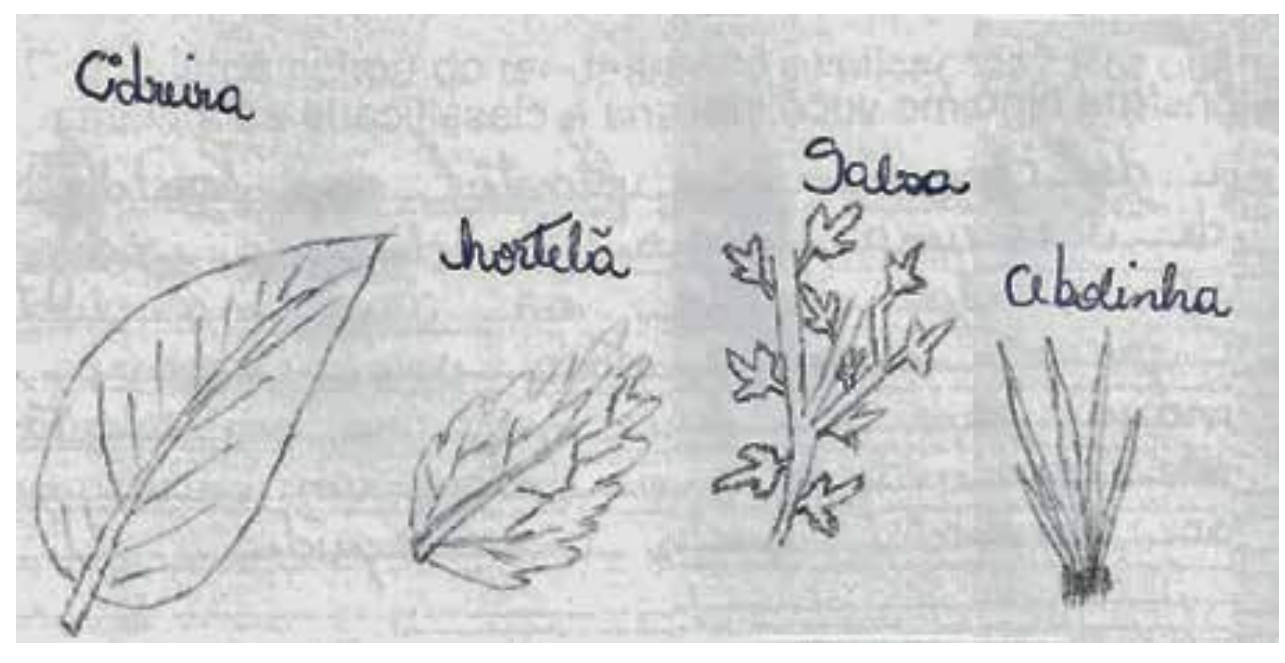

Fonte: Os autores (2017).

Para que os alunos reconhecessem o valor dessa etapa, ressaltou-se a importância de os resultados serem divulgados aos seus pares, notando-se uma eficaz participação dos alunos. No momento de divulgação das hipóteses, algumas explicações, mesmo que tímidas, começaram a aparecer. Isto também foi relatado pelo trabalho de Brito e Fireman (2016), no qual os alunos desenvolveram a habilidade de comunicar procedimentos de forma organizada e colaboraram escutando os colegas.

Foi possível perceber que algumas hipóteses levantadas não eram completamente coerentes com o que se objetivava resolver no problema, mas, fundamentando-se em Carvalho (2016), as hipóteses que convergem ao "erro" também são essenciais para a construção do conhecimento. Zompero, Gonçalves e Laburú, (2017, p. 426) comentam sobre este modo como o professor age: "com respeito e zelo, ele os deixa conscientes de suas incoerências argumentativas, cria questionamentos intencionais para que os estudantes se atentem a informações ignoradas e relações precipitadas". O professor deve saber contrastar as respostas dos alunos, quando estas não forem adequadas para explicar o fenômeno (BRICCIA, 2016). 
Esse momento proporcionou, ainda, o início da linguagem científico-argumentativa (CARVALHO, 2016), à medida que os alunos organizaram ideias para defender suas respostas. Observou-se que o diálogo aprimorou as explicações da turma e permitiu que eles realmente passassem da ação manipulativa para a atividade intelectual, pois "desenvolveram raciocínios para explicar o que fizeram na atividade. De tal modo, tomaram consciência de suas ações" (BRITO; FIREMAN, 2016, p. 139).

Senra e Braga (2014) salientam o desenvolvimento da capacidade de argumentação nos alunos em atividades experimentais investigativas. Em nosso trabalho, enquanto divididos em grupos, os alunos expuseram seu ponto de vista e questionaram as opiniões dos colegas, por vezes diferentes das suas; quando, porém, divulgaram suas hipóteses para toda a turma, argumentaram sobre o porquê acreditavam que responderam corretamente.

A perspectiva investigativa que se desejou explorar foi desvelada ao longo de toda a sequência de ensino, desde o problema inicial, em que utilizaram a imaginação atrelada aos conhecimentos prévios sobre plantas, até o segundo problema, de caráter prático. Neste, foi possível contextualizar e tornar significativo o conhecimento científico; assim, os alunos puderam criar relações do problema resolvido com situações cotidianas (CARVALHO et al., 1998).

No Ensino de Ciências por Investigação, somente depois que os alunos compreendem os conceitos trabalhados ao longo das atividades é que a eles são apresentadas as definições destes conceitos (CARVALHO, 2014). Por isso, a Sequência de Ensino Investigativa deste trabalho foi finalizada com a leitura de textos sobre o sistema sensorial presentes no livro didático, sistematizando o conteúdo em uma linguagem formal.

Em nossa Sequência de Ensino Investigativa atentou-se também à maneira como o aluno escreve, pois há uma diferença na escrita das hipóteses no início da aula quando comparadas com as respostas do questionário ao fim da aula. Nesse último instrumento, aparecem com mais frequência termos científicos, como tato, olfato, visão e receptores olfativos, resultado das atividades propostas.

Por fim, assinala-se que a sequência proporcionou o desenvolvimento da criatividade e reflexão pelos alunos, por exemplo ao formularem hipóteses para as questões-problema ou quando sistematizaram seus conhecimentos em grupo, assim como permitiu que os alunos compreendessem um pouco mais a natureza da ciência, que faz parte do processo de alfabetização científica (SASSERON; CARVALHO, 2011).

\section{CONSIDERAÇÕES FINAIS}

Ao longo desta pesquisa a abordagem da aprendizagem dos conteúdos do sistema sensorial por investigação, proporcionou uma atividade intelectual dos alunos por meio do trabalho com a linguagem, demonstração e argumentação, que vão muito além de uma educação meramente expositiva. 
Os resultados registrados pelos alunos sobre a sequência de ensino, bem como os dizeres deles sobre a proposta, mostram que esta metodologia ativa de aprendizagem os dotou de autonomia e criatividade para supor espécimes de plantas passíveis de serem identificados, manifestando efeitos de sentidos que podem ser produzidos e trabalhados em aulas de Ciências.

Em termos de alfabetização científica, diríamos que as aulas de ciências também podem contribuir para que os alunos possam ler, compreender e produzir textos, mobilizando os conhecimentos prévios a partir de uma postura ativa. Mais do que isso, a perspectiva discursiva mostra que a leitura e a escrita podem ir muito além de repetir dados ou informações consolidadas. Aí reside a importância de uma abordagem da aprendizagem que dê chances para os alunos desenvolverem as explicações buscando a construção de conceitos sobre o que se aprende em aulas de Ciências.

Como vimos, os (efeitos de) sentidos constroem-se na relação com o outro, com o cotidiano e com o conhecimento. Dessa forma, a sensibilidade para desenvolver leitura e escrita não é um dom inato, mas uma atividade intelectual que se constrói durante a aprendizagem. Nisso tudo importa trabalhar com as condições de produção de nossas aulas, pois, ao estimular os alunos a ler, criar hipóteses, discutir em grupos, expressar-se sobre o que já sabem, torna-se pertinente para que eles também possam desenvolver um espírito crítico ao manifestar seus conhecimentos sobre o discurso da ciência para além das aulas de Ciências.

Finalmente, destacamos que os indicativos deste estudo, que tangenciam e favorecem a alfabetização científica por meio de metodologias ativas em aulas de Ciências, merecem mais atenção na formação inicial do professor. Nisso, implica considerar possíveis indicativos desta pesquisa para debate e sua inserção nos cursos de Licenciatura, pois, se quisermos uma verdadeira efetivação de propostas inovadoras e interdisciplinares, devemos contar com uma participação conjunta de todos em processos de elaboração e aplicação da aprendizagem; um trabalho coletivo, em que universidade, escola e comunidade devem criar condições para promover a alfabetização científica e fortalecer seu funcionamento.

\section{AGRADECIMENTOS}

À Fundação Araucária de Desenvolvimento Científico e Tecnológico do Estado do Paraná, por ter financiado esta pesquisa.

\section{REFERÊNCIAS}

AZEVEDO, M. C. P. S. Ensino por investigação: problematizando as atividades em sala de aula. In: CARVALHO, A. M. P. (org.). Ensino de ciências: unindo a pesquisa e a prática. São Paulo: Pioneira Thomson Learning, 2006. p. 19-33.

BACHELARD, G. A formação do espírito científico: contribuição para uma psicanálise do conhecimento. Rio de Janeiro: Contraponto, 1996.

BIGGS, J. B. Aligning teaching for constructing learning. The higher education academy. 2003. Available from: http://www.heacademy.ac.uk/embedded_object.asp?id=21686\&filename=Biggs.

BRICCIA, V. Sobre a natureza da Ciência e o ensino. In: CARVALHO, A. M. P. (org.). Ensino de Ciências por investigação: condições para implementação em sala de aula. São Paulo: Cengage Learnig, 2016. p. 111128. 
BRITO, L. O.; FIREMAN, E. C. Ensino de Ciências por investigação: uma estratégia pedagógica para promoção da alfabetização científica nos primeiros anos do Ensino Fundamental. Revista Ensaio, Belo Horizonte, v. 18, n. 1, p. 123-146, jan./abr. 2016.

CAPECCHI, M. C. V. M. Problematização no ensino de Ciências. In: CARVALHO A. M. P. (org.). Ensino de Ciências por investigação: condições para implementação em sala de aula. São Paulo: Cengage Learnig, 2016. p. 21-39.

CARVALHO A. M. P. et al. Ciências no Ensino Fundamental: o conhecimento físico. São Paulo: Scipione, 1998.

CARVALHO, A. M. P. A pesquisa no ensino, sobre o ensino e sobre a reflexão dos professores sobre seus ensinos. Educação e Pesquisa, São Paulo, v. 28, n. 2, p. 57-67, jul./dez. 2002.

CARVALHO, A. M. P. Habilidades de professores para promover a enculturação científica. Contexto e Educação, São Paulo, n. 77, p. 25-49, jan./jun. 2007. Recuperado de: https://www.revistas.unijui.edu.br/index.php/contextoeducacao/article/viewFile/1084/83.

CARVALHO, A. M. P. Demonstrações investigativas. In: CARVALHO, A. M. P. (org.). Calor e temperatura: um ensino por investigação. São Paulo: Livraria da Física, 2014. p. 44-70.

CARVALHO, A. M. P. O ensino de Ciências e a proposição de sequências investigativas. CARVALHO, A. M. P. (org.). Ensino de Ciências por investigação: condições para implementação em sala de aula. São Paulo: Cengage Learnig, 2016. p. 1-39.

DAHMS, M. L. Problem Based Learning in Engineering Education. 12th. ed. Caxias do Sul, RS, Brazil: Active Learning in Engineering Education Workshop, 2014.

DELIZOICOV, D.; ANGOTTI, J. A.; PERNAMBUCO, M. M. Ensino de Ciências: fundamentos e métodos. 4. ed. São Paulo: Cortez, 2011. p. 31-42.

FELDER, R. M.; BRENT, R. Active Learning: An Introduction. ASQ Higher Education Brief, v. 2, n. 4, 2009. Available from: http://www4.ncsu.edu/unity/lockers/users/f/felder/public/Papers/ALpaper(ASQ).pdf.

JUSTICE, C. et al. Inquiry-based learning in higher education: administrators perspectives on integrating inquiry pedagogy into the curriculum. Higher Education, v. 58, n. 6, p. 841-855, 2009. Available from: https://link.springer.com/article/10.1007\%2Fs10734-009-92287.

KRASILCHIK, M. Prática de ensino de Biologia. 4. ed. São Paulo: Edusp, 2011.

LEMKE, J. L. Aprender a Hablar Ciencia: lenguaje, aprendizaje y valores. Espanha: Paidós, 1997.

MORAN, J. Metodologias ativas para uma aprendizagem mais profunda. In: BACICH, L. J. MORAN (org.). Metodologias ativas para uma educação inovadora: uma abordagem teórico-prática. Porto Alegre: Artmed, 2018. p. 1-25.

MUNFORD, D.; LIMA, M. E. C. C. Ensinar Ciências por investigação: Em quê estamos de acordo? Ensaio, Belo Horizonte, v. 9, n. 1. p. 89-111, jan./jun., 2007. Disponível em: http://dx.doi.org/10.1590/198321172007090107.

OLIVEIRA, C. M. A. O que se fala e se escreve nas aulas de Ciências? In: CARVALHO, A. M. P. (org.). Ensino de Ciências por investigação: condições para implementação em sala de aula. São Paulo: Cengage Learnig, 2016. p. 63-75.

ORLANDI, E. P. A linguagem e seu funcionamento: as formas de discurso. 4. ed. Campinas: Pontes, 2006. ORLANDI, E. P. Interpretação: autoria, leitura e efeitos do trabalho simbólico. 6. ed. Campinas: Pontes, 2012a.

ORLANDI, E. P. Discurso em análise: sujeito, sentido e ideologia. 2. ed. Campinas: Pontes, 2012b.

ORLANDI, E. P. Análise de discurso: princípios e procedimentos. 11. ed. Campinas: Pontes, 2013.

PARANÁ. Secretaria de Estado da Educação. Diretrizes Curriculares da Educação Básica - Ciências. Curitiba: SEED-PR, 2008.

PARENTE, A. G. L. Práticas de investigação no ensino de Ciências: percurso de formação de professores. 2012, 234f. Tese (Doutorado em Educação para a Ciência) - Universidade Estadual Paulista,. Programa de Pós-Graduação em Educação para a Ciência, Bauru, 2012.

PÊCHEUX, M. O discurso: estrutura ou acontecimento. 3. ed. Campinas: Pontes, 2002.

PÊCHEUX, M. Análise de discurso: textos escolhidos por Eni Orlandi. 3. ed. Campinas: Pontes, 2012.

POZO, J. I.; GÓMEZ-CRESPO, M. A. A aprendizagem e o ensino de Ciências: do conhecimento cotidiano ao científico. 5. ed. Porto Alegre: Artmed, 2009.

POZO, J. I.; GÓMEZ-CRESPO, M. A. La solución de problemas en Ciencias de la Natureza. In: POZO, J. I. (ed.). Solución de problemas. Madrid: Santillana; Aula XXI, 1994. 
PRINCE, M. Does Active Learning Work? A Review of the Research. Journal of Engineering Education, v. 93, n. 3, p. 223-231, 2004. Available from: https://onlinelibrary.wiley.com/doi/abs/10.1002/j.2168-9830.2004. tb00809.x.

RUPPELT, B. et al. Plantas medicinais: utilizadas na região Oeste do Paraná. Curitiba: UFPR, 2015.

SANTOS, E. I. Ciências nos anos finais do Ensino Fundamental: produção de atividades em uma perspectiva sócio-histórica. São Paulo: Anzol, 2012.

SASSERON, L. H.; CARVALHO, A. M. P. Almejando a alfabetização científica no Ensino Fundamental: a proposição e a procura de indicadores do processo. Investigações em Ensino de Ciências, v. 13, n. 3, p. 333-352, 2008. Disponível em: https://www.if.ufrgs.br/cref/ojs/index.php/ienci/article/view/445/263. SASSERON, L. H.; CARVALHO, A. M. P. Alfabetização científica: uma revisão bibliográfica. Investigações em Ensino de Ciências, Porto Alegre, v. 16, n. 1, p. 59-77, 2011. Disponível em: https://www.if.ufrgs.br/cref/ojs/index.php/ienci/article/view/246.

SCARPA, D. L.; SILVA, M. B. A Biologia e o ensino de Ciências por investigação: dificuldades e possibilidades. In: CARVALHO, A. M. P. (org.). Ensino de Ciências por investigação: condições para implementação em sala se aula. São Paulo: Cengage Learnig, 2016. p. 129-152.

SENRA, C. P.; BRAGA, M. Pensando a natureza da ciência a partir de atividades experimentais investigativas numa escola de formação profissional. Caderno Brasileiro de Ensino de Física, v. 31, n. 1, p. 7-29, abr. 2014. Disponível em: https://periodicos.ufsc.br/index.php/fisica/article/viewFile/2175-7941.2014v31n1p7/26465.

SOLINO, A. P.; GEHLEN, S. T. Abordagem temática freireana e o ensino de Ciências por investigação: possíveis relações epistemológicas e pedagógicas. Investigações em ensino de Ciências, v. 19, n. 1, p. 141162, 2014.

TRIVELATO, S. L. F.; TONIDANDEL, S. M. R. Ensino por investigação: eixos organizadores para sequências de ensino de Biologia. Revista Ensaio, Belo Horizonte, v. 17, n. especial, p. 97-114, nov. 2015. Disponível em: http://www.scielo.br/pdf/epec/v17nspe/1983-2117-epec-17-0s-00097.pdf.

VASCONCELLOS, C. S. Construção do conhecimento em sala de aula. 15. ed. São Paulo: Libertad, 2004. WESTWOOD, P. The problem with problems: Potential difficulties in implementing problem based learning as the core method in primary school mathematics. Australian Journal of Learning Difficulties, Londres, v. 16, n. 1, p. 5-18, abr. 2011. Available from: https://www.tandfonline.com/doi/abs/10.1080/1940 4158.2011.563475.

ZOMPERO, A. F.; GONÇALVES, C. E. S.; LABURÚ, C. E. Atividades de investigação na disciplina de Ciências e desenvolvimento de habilidades cognitivas relacionadas a funções executivas. Ciência Educação, Bauru, v. 23, n. 2, p. 419-436, 2017. Disponível em: http://www.scielo.br/scielo.php?pid=S1516=00419-\&scriptsci_abstract\&tlng=pt

ZOMPERO, A. F.; LABURÚ, C. E. Atividades investigativas no ensino de Ciências: aspectos históricos e diferentes abordagens. Revista Ensaio, Belo Horizonte, v. 13, n. 3, 2011. Disponível em: http://www.scielo. br/pdf/epec/v13n3/1983-2117-epec-13-03-00067.pdf. 